\title{
Efecto de células alimentadoras inactivadas de dos segmentos del oviducto en el desarrollo in vitro de embriones bovinos
}

\author{
Effect of inactivated feeder cells of two segments of the oviduct on the in vitro \\ development of bovine embryos
}

Gleni T. Segura ${ }^{1,3}$, Marigeidy Santiago ${ }^{2}$, Jenin V. Cortez $^{1}$, Nilton L. Murga ${ }^{1}$

\section{Resumen}

\begin{abstract}
El objetivo del estudio fue evaluar el efecto de células alimentadoras inactivadas (sistema feeder layer) provenientes de dos segmentos del oviducto bovino (istmo y ámpula) en el desarrollo in vitro de embriones bovinos. Se generaron líneas celulares de segmentos del istmo y ámpula para posteriormente ser inactivadas con mitomicina $\mathrm{C}$ $(40 \mu \mathrm{g} / \mathrm{ml})$ para inhibir su capacidad de división y eliminar la competencia por nutrientes con los embriones. Se maduraron in vitro ovocitos bovinos por $24 \mathrm{~h}$ y fueron fertilizados por $18 \mathrm{~h}$ en cultivo convencional con semen bovino Brangus. Los ovocitos supuestamente fertilizados fueron cultivados por siete días en el sistema feeder layer con células de istmo y ámpula separadamente a una concentración de $1.44 \times 10^{5}$ células $/ \mathrm{ml}$. Se obtuvo mejores resultados de producción de embriones bovinos in vitro con células ampulares $(280 / 84 ; 30 \%)$ en comparación con las células del istmo $(278 / 75 ; 26.9 \%)$ y el grupo control $(275 / 73 ; 26.5 \%)$ realizado en un sistema convencional. Se concluye que las células del oviducto pueden cumplir funciones similares a las que cumple el oviducto en el proceso in vivo, mejorando la producción in vitro de embriones.
\end{abstract}

Palabras clave: mitomicina $C$; células oviductuales; sistema con capa de alimentación; inactivación celular

\footnotetext{
${ }^{1}$ Laboratorio de Biotecnología Animal, Reproducción y Mejoramiento Genético, Instituto de Investigación en Ganadería y Biotecnología, Universidad Nacional Toribio Rodríguez de Mendoza, Chachapoyas, Perú

${ }^{2}$ Facultad de Ingeniería Zootecnista, Agronegocios y Biotecnología, Universidad Nacional Toribio Rodríguez de Mendoza, Chachapoyas, Perú

${ }^{3}$ E-mail: glenytatty@gmail.com
} 
The aim of this study was to evaluate the effect of inactivated feeder cells (feeder layer system) from two segments of the bovine oviduct (isthmus and ampulla) in the in vitro development of bovine embryos. Cell lines from segments of the isthmus and ampulla were generated and subsequently inactivated with mitomycin $\mathrm{C}(40 \mu \mathrm{g} / \mathrm{ml})$ to inhibit their ability to divide and eliminate competition for nutrients with embryos. Bovine oocytes were matured in vitro for $24 \mathrm{~h}$ and were fertilized for $18 \mathrm{~h}$ in conventional culture with Brangus bovine semen. The expected fertilized oocytes were cultured for seven days in the feeder layer system with isthmus and ampulla cells separately at a concentration of $1.44 \times 105$ cells $/ \mathrm{ml}$. The best results in the production of in vitro bovine embryos were obtained with ampullary cells $(280 / 84,30 \%)$ in comparison with the isthmus cells $(278 / 75$, $26.9 \%)$ and the control group $(275 / 73,26.5 \%)$ in a conventional system. It is concluded that the cells of the oviduct can fulfill functions like those that the oviduct fulfills in the in vivo process, improving the in vitro production of embryos.

Key words: mitomycin C; oviductual cells; feeder layer system; cellular inactivation

\section{INTRODUCCIÓN}

El cultivo con células alimentadoras, también conocido como sistemas de feeder layer es una idea atractiva de cultivar embriones tempranos en una monocapa de células oviductales o células uterinas. Este concepto supone que la monocapa proporciona algún estímulo específico al desarrollo del embrión o de alguna manera regula el ambiente para el desarrollo (Ellington et al., 1990). También sugiere que las células monocapa en cultivo deberían reflejar la actividad del mismo tipo de célula in vivo (Eyestone y First, 1989).

El uso de células alimentadoras en cultivo de embriones proporciona un estímulo para el desarrollo de los embriones, siendo los más utilizados el cultivo con vesículas extracelulares y células oviductuales (Hamdi, 2013), técnica que ha sido utilizado con células del tracto reproductivo para cultivar embriones in vitro no solo en bovinos sino también en ovinos (Dashti et al., 2016).
Existen estudios con células alimentadoras de oviducto las cuales han sido utilizadas en ovinos y bovinos con el objetivo de mejorar el desarrollo in vitro de los embriones y comprender los mecanismos de apoyo que brindan las células en el desarrollo embrionario (Ellington et al., 1990). El cultivo con células alimentadoras (sistema feeder layer) puede disminuir el estrés oxidativo a través de las funciones químicas benéficas que estas células producen (Mermillod et al., 1993). Es así que el objetivo de este estudio fue evaluar el efecto de células alimentadoras inactivadas provenientes de dos segmentos del oviducto bovino (istmo y ámpula) en el desarrollo in vitro de embriones bovinos.

\section{Materiales y Métodos}

\section{Localización del Estudio}

El estudio se realizó en el Laboratorio de Biotecnología Animal, Reproducción y Mejoramiento Genético del Instituto en Ganadería y Biotecnología, Universidad Nacio- 
nal Toribio Rodríguez de Mendoza, región Amazonas, Perú.

\section{Recolección del Tejido}

La muestra de tejido del istmo y ámpula del oviducto se recolectó del útero de una vaca cruzada Brown Swiss x criollo, mayor a dos partos, en condición corporal 3 y con actividad reproductiva (ciclando). El útero fue retirado luego del beneficio del animal y fue colocado en un recipiente isotérmico con solución salina $0.9 \%$ y a temperatura de 35 $37^{\circ} \mathrm{C}$ para su transporte al laboratorio.

\section{Obtención de las células alimentadoras (feeder layer)}

Los productos químicos y los medios de cultivo utilizados fueron adquiridos de Sigma Chemical Co. (EEUU) y los materiales de plástico desechable de Nunc (Roskilde, Dinamarca) a menos que se especifique lo contrario.

En el laboratorio se retiró el tejido conectivo de los dos segmentos. Cada extremo del oviducto fue cerrado por una sutura quirúrgica estéril. Se lavó y desinfectó con etanol cada segmento del oviducto. Se retiró la capa externa de cada segmento y la capa interna fue colocada en una placa petri dentro de la cabina de bioseguridad, donde se realizó una digestión mecánica. Luego se procedió a realizar múltiples lavados con buffer fosfato salino (PBS) y antibióticos y se sometió a digestión enzimática por $18 \mathrm{~h}$ en 10 $\mathrm{ml}$ de colagenasa $(1 \mathrm{mg} / \mathrm{ml}$ en medio DMEMF12 suplementado con $0.025 \mathrm{mg} / \mathrm{ml} \mathrm{de}$ estreptomicina y $10 \% \mathrm{SFB}$ ) a $37^{\circ} \mathrm{C}$ y con agitación orbital. Luego se agitó vigorosamente para desprender células que aún pudieran encontrarse adheridas al mismo. Se dejó reposar por $3 \mathrm{~min}$ y se recuperó el sobrenadante, siendo sembrado en placas petri de 35 mm estériles. El volumen del cultivo se completó a $2 \mathrm{ml}$ con medio DMEM-F12 suplementado con $1 \mathrm{mM}$ de glutamina, $0.2 \mathrm{mM}$ de piruvato, $10 \mathrm{ng} / \mathrm{ml}$ de EGF (epidermal growth factor) y $30 \%$ de suero fetal bovino (SFB) y fue puesto en una incubadora (CCL-170B-8, ESCO) de $\mathrm{CO}_{2}$ a $38^{\circ} \mathrm{C}$ para el desarrollo de las células.

\section{Congelación de las Células Alimen- tadoras}

Cuando el crecimiento de las células llenó toda la placa de cultivo, se procedió a la identificación de aquellas placas donde las células tuvieron rápida división. Se inicio el proceso de congelación donde se sacó todo el medio de cultivo de las placas con células y se lavó varias veces con PBS, luego se agregó tripsina-EDTA al $0.025 \%$ para despegar las células crecidas, y posteriormente se inactivó la tripsina adicionando DMEN F12 suplementado con $10 \%$ SFB. Cuando las células se despegaron, todo el contenido fue puesto en tubos de $15 \mathrm{ml}$ y centrifugado por $489 \mathrm{~g}$ por $5 \mathrm{~min}$; se cogió el pelet y se colocó en una placa de $60 \mathrm{~mm}$ en medio DMEN F12 suplementado con $10 \%$ de SFB y $8 \%$ de DMSO (dimetil sulfóxido). Luego se colocó a razón de $1 \mathrm{ml}$ en viales Nalgene de $2 \mathrm{ml}$ (Nalgene, Dinamarca) a una concentración de $3 \times 10^{6}$ células $/ \mathrm{ml}$. La congelación se llevó a cabo mediante un gradiente de $-1 \mathrm{C} / \mathrm{min}$, empleando el sistema Mister Frosty (Nalgene, Dinamarca) en el interior de un congelador comercial de $-80^{\circ} \mathrm{C}$. Luego de $4 \mathrm{~h}$ los viales fueron introducidos a un tanque de nitrógeno líquido $\left(-196^{\circ} \mathrm{C}\right)$.

\section{Recolección de Ovarios}

Se recolectaron 20 ovarios por repetición por semana del centro de beneficio de Chachapoyas, Amazonas. Las vacas eran Brown Swiss x criollo, de dos a más partos y con condición corporal de 2.5-4.0. Los ovarios fueron transportados al laboratorio en cloruro de sodio $(\mathrm{NaCl})$ al $0.9 \%$ (wt/vol) con $0.025 \mathrm{mg} / \mathrm{ml}$ de estreptomicina, temperado a 35- $37^{\circ} \mathrm{C}$.

\section{Maduración in vitro de Ovocitos (MIV)}

Los folículos de 2 a $6 \mathrm{~mm}$ fueron aspirados con aguja $18 \mathrm{G}$ acoplada a una jeringa. El líquido folicular fue colectado en tubos de 
$15 \mathrm{ml}$ y mantenido por $15 \mathrm{~min}$ a $37^{\circ} \mathrm{C}$ para sedimentar. Para la búsqueda de los ovocitos se retiró el sedimento y se mezcló con medio de manipulación (TCM-199 suplementado con $4 \mathrm{mM}$ de bicarbonato, $18 \mathrm{mM}$ de Hepes, $10 \%$ de SFB y $50 \mu \mathrm{g} / \mathrm{ml}$ de gentamicina).

Se seleccionaron los ovocitos en clasificación 1 y 2, que son aquellos que presentan abundantes células de cúmulos y coloración homogénea del citoplasma (Liebfried y First, 1979; Sato et al., 1990). Para la maduración, se colocaron 25 ovocitos por pocillo por $24 \mathrm{~h}$ en una atmósfera humidificada con $5 \% \mathrm{CO}_{2}$ a $38.5^{\circ} \mathrm{C}$, en medio de maduración TCM-199 suplementado con $0.2 \mathrm{mM}$ de piruvato, $50 \mu \mathrm{g} / \mathrm{ml}$ de gentamicina, $0.01 \mathrm{UI} /$ $\mathrm{ml}$ de hormona folículo estimulante (FSH), $0.01 \mathrm{UI} / \mathrm{ml}$ de hormona luteinizante ( $\mathrm{LH}), 0.6$ $\mathrm{mM}$ de glutamina, $10 \mathrm{ng} / \mathrm{ml}$ factor de crecimiento epidermal (EGF), $1 \mu \mathrm{g} / \mathrm{ml}$ de estradiol y 10\% SFB (Vajta et al., 2000).

\section{Fecundación in vitro de Ovocitos (FIV)}

Los ovocitos madurados fueron juntados en una incubadora por $18 \mathrm{~h}$ en una atmosfera humidificada a $38.5{ }^{\circ} \mathrm{C}$ y $5 \% \mathrm{CO}_{2}$ con los espermatozoides lavados, seleccionados y capacitados por el método de Percoll (Parrish et al., 1995) de un toro Brangus en medio de fecundación TALP-FIV (Vajta, 2000), suplementado con $2 \mathrm{mM}$ de piruvato de sodio, $50 \mu \mathrm{g} / \mathrm{ml}$ de gentamicina, $0.03 \mathrm{mg} / \mathrm{ml}$ de heparina y $3 \mathrm{mg} / \mathrm{ml}$ de BSA-FAF.

\section{Inactivación de Células Alimentadoras}

Las células del istmo y ámpula fueron descongeladas bajo inmersión en baño maría a $37^{\circ} \mathrm{C}$, y se esperó a tener las células al $90 \%$ de confluencia (Figura 1), para ser inactivadas mediante incubación en una atmosfera humidificada a $38.5{ }^{\circ} \mathrm{C}$ y $5 \% \mathrm{CO}_{2}$ con $40 \mu \mathrm{g} / \mathrm{ml}$ de mitomicina C (MCC) durante $5 \mathrm{~h}$. Después de la inactivación, se retiró el medio que contenía las placas y las células se lavaron dos veces con PBS, para luego ser disociadas con tripsina-EDTA al $0.025 \%$. Luego se inactivó la tripsina adi- cionando DMEN F12 suplementado con 10\% SFB.

\section{Cultivo de Células Alimentadoras Inactivadas (sistema feeder layer)}

Las células despegadas e inactivadas se sembraron en placas de cuatro pocillos (Nunc, Roskilde, Dinamarca), a una densidad de 1.44 x $10^{5}$ células/pocillo (Goméz et al., 2010) en medio DMEN F12. Pasadas las $24 \mathrm{~h}$ de cultivo el medio DMEN F12 fue remplazado con el medio SOF base (Vajta et al., 2000) suplementado con $0.044 \mathrm{~g} / 1$ de piruvato de sodio, $0.039 \mathrm{~g} / \mathrm{l}$ de L-glutamina, $3.0 \mathrm{mg} / \mathrm{ml}$ de suero albúmina bovina (BSA-FAF), $1 \mathrm{X}$ de amino ácidos esenciales, $1 \mathrm{X}$ de amino ácidos no esenciales, $10 \mathrm{mg} / \mathrm{ml}$ de EGF, $0.1 \mathrm{mg} / \mathrm{ml}$ de ácido cítrico, $0.5 \mathrm{mg} / \mathrm{ml}$ de myo-inositol, 50 $\mu \mathrm{g} / \mathrm{ml}$ de gentamicina y $2 \%$ de SFB.

\section{Cultivo de Cigotos en el Sistema Feeder Layer}

Los presuntos cigotos fueron desnudados por pipeteo y colocados en las placas de cuatro pocillos que contenían las células de istmo y ámpula inactivadas en el medio de cultivo SOF mencionado anteriormente. Luego fueron incubadas a $38.5{ }^{\circ} \mathrm{C}, 90 \%$ de humedad y mezcla de gases $\left(90 \% \mathrm{~N}, 5 \% \mathrm{CO}_{2}\right.$, $5 \% \mathrm{O}_{2}$ ) en bolsas herméticas.

\section{Resultados}

Se obtuvieron 500 ovocitos clasificados como 1 y 2 por cada tratamiento, los cuales pasaron por un proceso de maduración y fecundación. La evaluación a las 48 horas no demostró diferencia significativa en el porcentaje de clivaje de embriones (Cuadro 1). No obstante, en el desarrollo in vitro de los embriones (Figura 2; Cuadro 2) se encontró un porcentaje mayor de blastocistos al día 7 con el uso células alimentadoras inactivadas de ámpula en la etapa de cultivo en comparación al cultivo con células alimentadoras inactivadas de istmo y con el grupo control $(\mathrm{p}<0.05)$. 

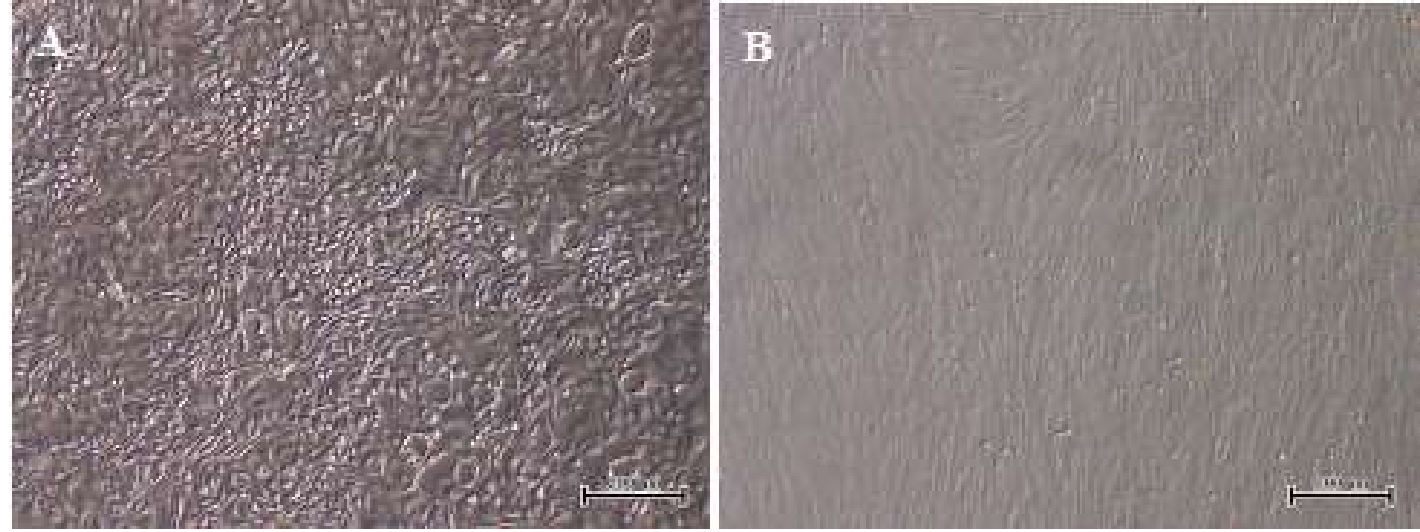

Figura 1. Cultivo in vitro de células alimentadoras: A) Células de ámpula crecidas; B) Células del istmo crecidas

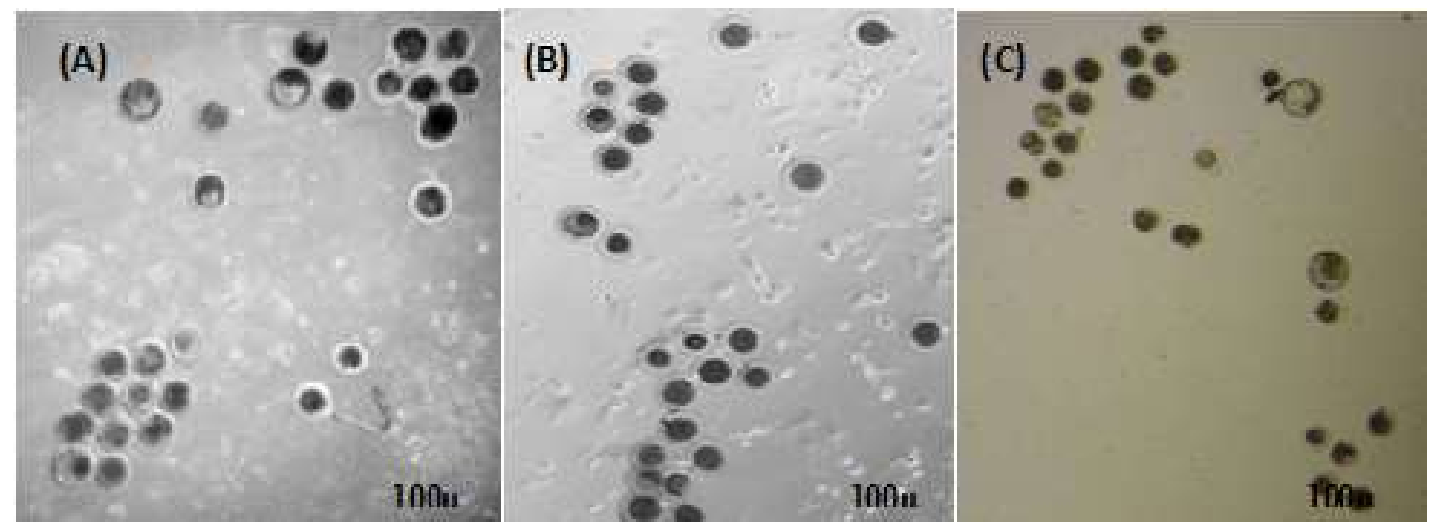

Figura 2. Blastocistos de 7 días: A) células alimentadoras de ámpula; B) células alimentadoras de istmo; C) grupo control

\section{Discusión}

Las células utilizadas como capa alimentadora (feeder layer) son unidades orgánicas que están en constante división y para lo cual consumen gran cantidad de nutrientes del medio de cultivo por lo que es muy importante utilizar un método que detenga el crecimiento de las células, pero que metabólicamente sigan activas. En el presente trabajo se utilizó mitomicina $\mathrm{C}$ como aditivo capaz de detener el crecimiento celular (Llames et al., 2015).
Se tenía la idea de que el embrión era el único responsable de su desarrollo; sin embargo, actualmente se conoce que el ambiente que le proporciona el oviducto en el transcurso de su desarrollo tiene fundamental importancia (Watkins et al., 2008), lo cual se puede observar en los resultados del estudio, donde el uso de células que forman parte de la estructura del oviducto (istmo y ámpula) han permitido obtener embriones por encima del promedio $(26.5 \%)$ del control en un sistema convencional. 
Cuadro 1. Clivaje de embriones in vitro a las 48 horas de cultivo con células alimentadoras inactivadas (istmo y ámpula del oviducto)

\begin{tabular}{lcccc}
\hline Grupo & $\begin{array}{c}\text { Ovocitos } \\
(\mathrm{n})\end{array}$ & $\begin{array}{c}\mathrm{N}^{\circ} \text { de ovocitos } \\
\text { madurados (\%) }\end{array}$ & $\begin{array}{c}\text { Ovocitos } \\
\text { fecundados (n) }\end{array}$ & $\begin{array}{c}\mathrm{N}^{\circ} \text { de clivados (\%) } \\
\text { a las 48 h }\end{array}$ \\
\hline Ámpula & 500 & $280(56)$ & 280 & $125(44.6 \pm 1.2)^{\mathrm{a}}$ \\
Istmo & 500 & $278(55.6)$ & 278 & $118(42.4 \pm 1.1)^{\mathrm{a}}$ \\
Control & 500 & $275(55)$ & 275 & $117(42.5 \pm 1.2)^{\mathrm{a}}$ \\
\hline
\end{tabular}

a,b Superíndices diferentes dentro de columnas indican diferencia estadística $(p<0.05)$

Cuadro 2. Desarrollo in vitro de blastocistos bovinos en cultivo con células alimentadoras inactivadas (sistema feeder layer) provenientes de dos segmentos del oviducto (istmo y ámpula) (500 ovocitos)

\begin{tabular}{lc}
\hline Grupo & $\begin{array}{c}\text { N. }{ }^{\circ} \text { de blastocistos (día } \\
7)(\%)\end{array}$ \\
\hline Ámpula & $84(30.0 \pm 2.3)^{\mathrm{a}}$ \\
Istmo & $75(26.9 \pm 2.2)^{\mathrm{b}}$ \\
Control & $73(26.5 \pm 2.2)^{\mathrm{b}}$ \\
\hline
\end{tabular}

a,b Superíndices diferentes dentro de columnas indican diferencia estadística $(p<0.05)$

La aplicabilidad y beneficios que tiene el uso de células alimentadoras inactivadas en la producción de embriones in vitro en diversas especies es notorio. Dashti et al. (2016) utilizaron células alimentadoras de istmo y ámpula en su cultivo de producción de embriones in vitro en ovinos obteniendo mejores resultados en porcentaje de producción de blastocistos con células de istmo (45.4\%) que con el uso de células de ámpula $(36.6 \%)$, mientras que Hamdi (2013) no encontró diferencia al evaluar células de toda la estructura del oviducto bovino en la producción y calidad de embriones in vitro en bovinos. En el presente estudio, las células alimentadoras de ámpula presentaron un mejor efecto en la producción de embriones in vitro en bovinos $(30.0 \% \pm 2.3)$ que las células del istmo $(26.9 \%$ \pm 2.2 ).

\section{Conclusión}

La utilización de células del ámpula del oviducto como células alimentadoras en el proceso de producción de embriones in vitro en bovinos aumenta el porcentaje de producción de embriones.

\section{Agradecimientos}

Los autores agradecen al Instituto de Investigación en Ganadería y Biotecnología de la Universidad Nacional Toribio Rodríguez de Mendoza de Amazonas por autorizar la investigación en los ambientes del Laboratorio de Biotecnología Animal Reproducción y Mejoramiento Genético.

\section{LiTteratura CitAdA}

1. Dashti S, Shahneh AZ, Kohram H, Zhandi M, Davachi ND. 2016. Differential inûuence of ovine oviduct ampullary and isthmic derived epithelial cells on in vitro early embryo develop- 
ment and kinetic. Small Ruminant Res 136: 197-201. doi: 10.1016/j.smallrumres.2016.02.007

2. Ellington JE, Farrell PB, Simkin ME, Foote RH, Goldman EE, McGrath AB. 1990. Development and survival after transfer of cow embryos cultured from 1-2 cells to morulae or blastocysts in rabbit oviducts or in a simple medium wit bovine oviduct epithelial cells. J Reprod Fertil 89: 293-299. doi: 10.1530/ jrf.0.0890293

3. Eyestone WH, First NL. 1989. Coculture of early cattle embryos to the blastocyst stage with oviducal tissue or in conditioned medium. J Reprod Fertil 85: 715-720. doi: 10.1530/jrf.0.0850715

4. Gómez MC, Serrano MA, Pope CE, Jenkins JA, Biancardi MN, López M, Dumas C, et al. 2010. Derivation of cat embryonic stem-like cells from in vitro-produced blastocysts on homologous and heterologous feeder cells. Theriogenology 7: 498-515. doi: 10.1016/ j.theriogenology.2010.05.023

5. Hamdi M. 2013. Efecto de las células epiteliales del oviducto bovino y de sus vesículas extracelulares en el cultivo embrionario bovino in vitro. Tesis de Maestría. Valencia, España: Univ. Politécnica de Valencia. $87 \mathrm{p}$.

6. Liebfried L, First N. 1979. Characterization of bovine follicular oocytes and their ability to mature in vitro. J Anim Sci 48: 76-86. doi: 10.2527/ jas1979.48176x
7. Llames S, García-Pérez E, Meana Á, Larcher F, del Río M. 2015. Feederlayer cell actions and applications. Tissue Eng Regen Med 21: 345-353. doi: 10.1089/ten.TEB.2014.0547

8. Mermillod P, Vansteenbrugge A, Wils C, Mourmeaux JL, Massip A, Dessy F. 1993. Characterization of the embryotrophic activity of exogenous protein-free oviduct-conditioned medium used in culture of cattle embryos. Biol Reprod 49: 582-587. doi: 10.1095/ biolreprod49.3.582

9. Parrish JJ, Krogenaes A, SuskoParrish JL. 1995. Effect of bovine sperm separation by swim up or percoll on success of in vitro fertilization and embryo development. Theriogenology 44: 859-870. doi: 10.1016/0093-691X(95)-00271-9

10. Sato E, Matsuo M, Miyamoto H. 1990. Meiotic maturation of bovine oocytes in vitro: improvement of meiotic competence by dibutyryl cyclic adenosine 3', 5' monophosphate. J Anim Sci 68: 1182-1187. doi: $10.2527 / 1990.6841182 x$

11. Vajta G, Peura TT, Holm P, Páldi A, Greve T, Trounson AO, Callesen $H$. 2000. New method for culture of zonaincluded or zona free embryosthe wellof-the-well (WOW) system. Mol Reprod Dev 55: 256-264. doi: 10.1002/ ( S I C I ) 1098 - $2795(200003)$ 55:3<256::AID-MRD3>3.0.CO;2-7

12. Watkins AJ, Papenbrock T, Fleming TP. 2008. The preimplantation embryo: handle with care. Semin Reprod Med 26: 175-185. doi: 10.1055/s-2008-1042956 